\title{
Uso de plantas medicinais no Ceará: uma revisão da literatura de 2008 a 2018
}

O estudo objetivou analisar as produções científicas da etnobotânica em sua relação com as plantas medicinais no Estado do Ceará, durante o período de 2008 a 2018. Trata-se de uma revisão integrativa da literatura de caráter descritivo, transversal com abordagem quantitativa. Diante dos fatos, a presente pesquisa se baseou pela seguinte pergunta norteadora: 'Qual foi a produção científica no período de 2008 a 2018 cuja temática se remete as plantas medicinais utilizadas no estado do Ceará, dentro do contexto da etnobotânica?'. Em toda busca integrativa encontrou-se um total de 27 produções, onde somente 19 atenderam aos critérios estabelecidos, dessa forma, define-se esse quantitativo na finalização do estudo. Portanto, conforme a presente revisão integrativa, a prevalência de trabalho em etnobotânica sobre plantas medicinais no período estabelecido no Ceará ainda é bastante baixa, evidenciando de um modo geral um campo que proporciona possibilidade a inserção dessa ciência.

Palavras-chave: Medicina Tradicional; Fitoterápicos; Nordeste.

\section{Use of medicinal plants in Ceará: a literature review from 2008 to}

\section{8}

The study aimed to analyze the scientific productions of ethnobotany in its relationship with medicinal plants in the State of Ceará, during the period from 2008 to 2018. It is an integrative review of the literature of a descriptive, transversal nature with a quantitative approach. Given the facts, this research was based on the following guiding question: 'What was the scientific production in the period from 2008 to 2018 whose theme refers to the medicinal plants used in the state of Ceará, within the context of ethnobotany?'. In all integrative search, a total of 27 productions were found, where only 19 met the established criteria, thus, this quantity is defined at the end of the study. Therefore, according to the present integrative review, the prevalence of work in ethnobotany on medicinal plants in the period established in Ceará is still quite low, showing in general a field that allows the insertion of this science.

Keywords: Traditional Medicine; Phytotherapics; Northeast.

Topic: Uso Sustentável da Biodiversidade

Reviewed anonymously in the process of blind peer.
Received: 03/08/2020

Approved: 18/09/2020
Francisco Glauber Peixoto Ferreira (iD

Universidade da Integração Internacional da Lusofonia Afro-Brasileira, Brasil http://lattes.cnpq.br/6898728780485440

http://orcid.org/0000-0002-3980-7253

fgpf.glauber@hotmail.com

Meiriane da Silva Pinheiro (iD

Universidade da Integração Internacional da Lusofonia Afro-Brasileira, Brasil http://lattes.cnpq.br/3977098368007773

http://orcid.org/0000-0002-2643-8911

meirianehistoriadora@gmail.com

Bárbara Eleodora Santiago Gomes (ic

Universidade da Integração Internacional da Lusofonia Afro-Brasileira, Brasi http://lattes.cnpq.br/7504427306460282

http://orcid.org/0000-0003-2872-9322

barbara@unilab.edu.br
Maria Ivanilda de Aguiar (iD)

Universidade da Integração Internacional da Lusofonia Afro-Brasileira, Brasil http://lattes.cnpq.br/5455983813192128

http://orcid.org/0000-0002-6147-2621

ivanilda@unilab.edu.br

\section{Referencing this:}

FERREIRA, F. G. P.; PINHEIRO, M. S.; GOMES, B. E. S.; AGUIAR, M. I. Uso de plantas medicinais no Ceará: uma revisão da literatura de 2008 a 2018. Revista Ibero Americana de Ciências Ambientais, v.11, n.5, p.198-209, 2020. DOI: http://doi.org/10.6008/CBPC21796858.2020 .005 .0020 


\section{INTRODUÇÃO}

A etnobotânica em seu conceito básico se remete a produção de conhecimento científico baseado no binômio homem e plantas, de modo que se estabeleça uma relação direta em que aborda aspectos culturais, sociais e histórico ao longo de séculos (ALCORN, 1995). Além disso, também tem sido caracterizada como uma disciplina científica que trabalha sobre uma abordagem nova, não agrupada em seu sentido amplo a outras já existentes (HAMILTON, et al., 2003).

Por outro lado, suas percepções têm sido basicamente voltadas para os estudos delimitados das plantas medicinais, ou seja, a flora como objeto de estudo conforme explanado por Cunha e Bortolotto (2011). Nessa perspectiva, não se pode descartar a possibilidade que esses conhecimentos milenares serviram de pontos norteadores em que visou direcionar o que hoje conhecemos como ciência dentro da etnobotânica (AMOROZO, 1996).

Através disso, os conhecimentos etnobotânicos se mostraram relevantes dentro do cenário contemporâneo dos produtos naturais bioativos, se tornando uma alternativa promissora no campo de pesquisa farmacológica e na fitoterapia na produção de produtos sintéticos e semissintéticos (MACIEL et al., 2002). Carvalho et al. (2013) elencou um ponto bastante peculiar, pois enfoca o manejo dessas práticas do preparo utilizando plantas cultiváveis não só para uso medicinal, mas também para alimentação e matéria prima na confecção de artesanatos e utensílios.

Em virtude de tais fatos, nota-se que há uma importância do envolvimento cultural do cultivo de plantas medicinais e as tradições locais, no que se refere a valores empregados pelo povo que reside em determinadas regiões pesquisadas (MIRANDA et al., 2008). Em complemento, o Brasil apresenta-se como um país propício a realização desse tipo de levantamento, pois de uma certa forma possui uma grande variedade de espécie para fins terapêuticos e outro quantitativo ainda maior até então não explorado (OLIVEIRA et al., 2009).

Perante uma abordagem mais prática, a etnobotânica na produção científica contemporânea está voltada para grupos de etnias que possuem uma relação mais forte com as plantas medicinais. Exemplo disso são os indígenas, que por sua vez preserva um conjunto de comportamentos culturais, dentre estes, a utilização das ervas medicinais nas mais diversas aplicabilidades (SANTOS et al., 2018).

Ainda nessa ótica, Apolinário (2013) cita que em território brasileiro esses conhecimentos em específico ganharam expansão desde os primórdios coloniais, em que os índios já possuíam habilidades tanto no reconhecimento de plantas quanto no modo de preparo de extratos, levando em consideração a ritualidade e o respeito por seus ancestrais. Nesse contexto, entende-se que em diversas partes do Brasil a etnobotânica foi ganhando espaço tanto do ponto de vista prático, como da cultura nas obras de diversos pesquisadores, como foi o caso da obra de Cristóvão Lisboa no estado do Maranhão, especificamente no século XVII (LINHARES et al., 2018).

No que tange a etnoecologia juntamente com a etnobotânica, é bem comum a realização de trabalhos nesse mesmo eixo, pois a primeira encontra-se em complemento com a segunda, a depender do 
ponto de vista em que o pesquisador se propõe em abordar. Sousa et al. (2015) ao se apropriar dessa associação, conseguiu êxito em relacionar tal técnica na vegetação de Palmeira Carnaúba no semiárido nordestino.

Já no Ceará, a caatinga possibilita a realização de pesquisas de maneira ampla e diversificada, pois o bioma possui características particulares para o surgimento de espécies nativas e endêmicas, promovendo um afunilamento no que tange os costumes e hábitos da inserção de plantas medicinais e para fins comestíveis dentro da rotina do sertanejo (SILVA et al., 2015).

Ademais, a caatinga apresenta peculiaridades que não são encontradas em outros biomas, isso pode ser explicado pelo fato deste possuir uma grande diversidade de espécie, principalmente quanto a vegetação e a geomorfologia, tornando o semiárido um vasto campo de extensa investigação botânica (BRASIL, 2009). Ainda nesse estado, a produção científica cearense dentro do campo da etnobotânica é desmembrada em suas subáreas, como é o caso da pesquisa etnográfica realizada em etnias indígenas, exemplo disso foi colocado por Pinto et al. (2018) ao promover uma publicação com os povos Tremembé da Barra do Mundaú. Nesse caso, o autor apontou com ênfase as questões sociais, em especial os avanços da indústria imobiliária nesse território, o que poderia culminar em danos culturais e patrimoniais naturais dessa população.

Outro ponto a se ressaltar é com relação as concentrações de estudos com espécies medicinais em uma parte do Nordeste, evidenciando uma delimitação por regiões mais propícia a realização de catalogação. Alguns poucos periódicos fogem à regra, como é o caso do distrito de Aratama, no Município de Assaré no Ceará, no qual Ribeiro et al. (2014) evidenciou um potencial terapêutico de plantas pertencente aquele território em específico. Esse recorte coloca em questão o vasto campo ainda não explorado nesse Estado, de modo a incentivar a investigação ampla e descentralizada em um único bioma.

Em outra perspectiva, é notório o quanto as percepções de uma cultura podem abrir caminho para a ampliação do arsenal cientifico, de maneira que as características empregadas pelo cenário influenciam diretamente na forma como o agricultor lida com cada tipo de planta. Em alternativa a essa hipótese, o Sertão Cearense possui uma heterogênea diversidade de solo e clima que por mais árida e seca que pareça, não deixa de ser uma singularidade própria. Para tanto, algumas cidades já possuem um comercio bastante consolidado de preparos naturais, fortalecendo o campo da etnobotânica como Crato, Barbalha, Santana do Cariri e Jardim (OLIVEIRA et al., 2007).

Simultaneamente a essa questão, nota-se que o conhecimento popular quanto a finalidade das plantas medicinais se encontra bastante disseminado nas pequenas cidades do Nordeste. Logo, Teixeira et al., (2014) ressaltou bastante em seu trabalho realizado na cidade de Sobral, também no Ceará, o mecanismo de comunicação e compartilhamento de saberes entre os habitantes desse município, visto que as tradições medicinais cumpriram e cumprem um papel de importância perante o estilo de vida dessa população, principalmente quanto ao aspecto cultural e religioso.

Dentro da modernidade capitalista, a base da etnobotânica ainda tenta permanecer intacta diante dos costumes modernos, como é o caso da comercialização de plantas medicinais na forma de preparos em extratos e garrafadas. Essa adaptação se tornou uma alternativa de uma fonte de renda para comunidades 
que possuem baixo poder aquisitivo, como mostrou Bispo et al. (2019) na cidade de Juazeiro do Norte, Ceará. Em Contrapartida, por mais que desperte um sentimento de consumismo, a cultura de quem produz se torna disseminada dentro do turismo econômico, além de ser um meio alternativo para indivíduos que não conseguem adquirir fármacos industrializados. Diante do exposto, esse estudo objetivou analisar as produções científicas da etnobotânica em sua relação com as plantas medicinais no Estado do Ceará, durante um período de dez anos (2008 a 2018), visando promover um levantamento sólido por meio da revisão integrativa da literatura.

\section{METODOLOGIA}

Trata-se de uma revisão integrativa da literatura de caráter descritivo, transversal com abordagem quantitativa. A revisão da literatura possibilita a obtenção de dados no intuito de construir conhecimento por meio do balanceamento produtivo e científico. Dessa forma, possibilita apontar o caminho de determinada temática e seu percurso no decorrer do tempo, com aplicabilidade no surgimento de novos trabalhos conforme necessidade e apontamento (BROOME, 2006).

A revisão da literatura segue um processo linear e sistemático, de modo que o pesquisador deve seguir etapas para construção dos resultados. Para tanto, o objetivo primordial desses passos metodológico é voltado para a replicabilidade fiel. Com isso, a revisão foi construída por meio da adoção de etapas, descritas conforme o método de Souza et al. (2010), que são: identificar o problema e por meio deste formular a pergunta norteadora para ser pesquisada nas bases de dados com os descritores estabelecidos; definir critérios de inclusão e exclusão para realização do levantamento de dados; identificação dos estudos selecionados; categorização dos estudos; interpretação dos resultados e análise; e concluindo com a apresentação da revisão por meio da síntese de conhecimentos.

Diante dos fatos, a presente pesquisa se baseou pela seguinte pergunta norteadora: "Qual foi a produção científica no período de 2008 a 2018 cuja temática se remete as plantas medicinais utilizadas no estado do Ceará, dentro do contexto da etnobotânica? ". Adiante, se definiu os descritores de busca em bases de dados, utilizou-se "etnobotânica"; "plantas medicinais"; "Ceará". Tal etapa se remete a busca sistematizada e formalizada a nível mundial por meio de combinação eletrônicas para construção de assunto e citações conforme temática de pesquisa (TOLEDO, 2008).

Com relação a busca propriamente dita, optou-se pelas seguintes bases de dados: Literatura LatinoAmericana em Ciências de Saúde (LILACS), Medical Literature Analysis and Retrieval Sistem on-line (Medline) e Scientific Electronic Library Online (SciELO). Durante a pesquisa nas duas primeiras bases de dados, LILACS e Medline, foram utilizados os operadores boleanos 'and' em todos os descritores de pesquisa, que resultou em: 'etnobotânica AND plantas medicinais AND Caatinga AND Ceará, respectivamente'. Na terceira e última base de dados, SciELO, não foi possível utilizar os descritores boleanos dessa forma, foi utilizado 'or, and $e$ and', que resultou em: 'etnobotânica AND plantas medicinais AND Ceará'.

As produções científicas utilizadas para a pesquisa, foram selecionadas por meio dos critérios de inclusão e exclusão, primeiramente. A segunda etapa, foram excluídos aqueles que apresentavam 
duplicidade, artigos de revisões e os que não respondiam à pergunta norteadora. A terceira e última etapa, foi por meio de uma análise na íntegra, lendo por completo todos os artigos, que resultou nos artigos finais utilizados na produção da revisão. Os trabalhos utilizados nesse estudo foram artigos publicados em revistas científicas, resumos simples e expandidos que abordassem a temática, trabalho de conclusão de curso, além de teses e dissertação com referência em etnobotânica.

\section{RESULTADOS E DISCUSSÃO}

Em toda busca integrativa encontrou-se um total de 27 produções, das quais, 19 atenderam aos critérios estabelecidos, dessa forma, define-se esse quantitativo na finalização do estudo. Especificamente na base de dados LILACS foram encontrados um total de 10 artigos, porém, somente 9 foram utilizados conforme o método de inclusão, e 1 retirado por apresentar duplicidade. Já na base de dados Mediline, resulta-se na busca total de 2 artigos, sendo que apenas um atendeu ao critério da temática. E como última base utilizada, a SciELO, obteve-se um total de 15 trabalhos, contudo, apenas 9 responderam à pergunta norteadora e 2 estava fora de contexto, os outros 4 eram resumos de eventos científico, que foram descartados por não apresentar data específica de publicação (Quadro 1).

Diante de uma perspectiva mais objetiva, boa parte dos estudos averiguados se remetem a promover um levantamento (Quadro 2) sobre o conhecimento de determinadas comunidades a respeito da medicina tradicional (MACEDO et al., 2013; RIBEIRO et al., 2014; PEREIRA et al., 2014; PEREIRA et al., 2014; SOARES et al., 2015; SILVA et al., 2015; OLIVEIRA et al., 2015; LEMOS et al., 2015; SANTOS et al., 2018), como é o caso do uso dos produtos naturais. Para tanto, esse fato está diretamente vinculado aos laços culturais que esses grupos estabelecem no decorrer de gerações, de modo a enfrentar os costumes da modernidade e prevalecer a ritualidade em forma de religião praticada por esses povos como afirma Oliveira et al. (2010). Já Zurlo et al. (1989) concordam que as pessoas que realizam a manipulação dessas plantas, como benzedores, raizeiros, raizeiras e pajés buscam um equilíbrio que vai além da compreensão científica, de modo a deixar em harmonia corpo e alma por meio do processo de cura.

Além disso, na presente pesquisa foi possível estabelecer uma direção com sentido a categoria de confecção desses produtos medicinais, que em sua maioria são espécies não convencionais e para fins de patologias inflamatória, especificamente ginecológicas (SANTOS et al., 2017; OLIVEIRA et al., 2012). Assim também como estudo taxonômico (RIBEIRO et al., 2013) e na perspectiva futurista da inserção dessa prática no Sistema Público de Saúde conforme particularidades (NASCIMENTO et al., 2013). Dessa forma, nota-se que a utilização das plantas medicinais pelos usuários do serviço de saúde com orientação de profissionais de nível superior tem se tornado cada vez mais comum, de modo que a ciência juntamente com o senso comum beneficiará essa inter-relação entre comunidade e academia conforme explana Souza et al. (2013).

Quadro 1: Fase de seleção dos estudos encontrados para compor a revisão dentro do período de 2008 a 2018 em etnobotânica no Estado do Ceará - Brasil.

\begin{tabular}{|l|l|l|l|l|}
\hline $\begin{array}{l}\text { Base de } \\
\text { dados }\end{array}$ & $\begin{array}{l}\text { Total } \\
\text { encontrado }\end{array}$ & $\begin{array}{l}\text { Fase } \\
\text { (inclusão/exclusão) }\end{array}$ & $\begin{array}{l}\text { Fase 2 (leitura de título e resumo/duplicidade/não } \\
\text { atende a pergunta) }\end{array}$ & $\begin{array}{l}\text { Fase 3 (leitura na } \\
\text { íntegra) }\end{array}$ \\
\hline LILACS & 10 & 9 & 9 & 9 \\
\hline
\end{tabular}




\begin{tabular}{|l|l|l|l|l|}
\hline Medline & 2 & 1 & 1 & 1 \\
\hline SciELO & 15 & 10 & 9 & 9 \\
\hline TOTAL & 27 & 20 & 19 & 19 \\
\hline
\end{tabular}

Quadro 2: Identificação e objetivo dos artigos selecionados para compor a revisão.

\begin{tabular}{|c|c|c|c|c|c|}
\hline $\begin{array}{l}\text { Base de } \\
\text { dados }\end{array}$ & Título & Idioma & Autores & Modalidade & Objetivo do estudo \\
\hline LILACS & $\begin{array}{lr}\text { Os } & \text { aspectos } \\
\text { etnobotânicos } & \text { da } \\
\text { copaíba } & \\
\end{array}$ & Português & ROSA; GOMES & $\begin{array}{l}\text { Revista Geografar, } \\
\text { Curitiba, v.4, n.1, p.59-77, } \\
2009\end{array}$ & $\begin{array}{l}\text { Analisar a relação do } \\
\text { homem com a natureza } \\
\text { por meio dos } \\
\text { conhecimentos } \\
\text { culturais da Copaíba. }\end{array}$ \\
\hline LILACS & $\begin{array}{l}\text { Plantas medicinais e sua } \\
\text { utilização pelas } \\
\text { comunidades do } \\
\text { Município de Sobral, } \\
\text { Ceará }\end{array}$ & Português & $\begin{array}{l}\text { NASCIMENTO, W. } \\
\text { M. C.; } \\
\text { MELO, O. F.; } \\
\text { SILVA, I. F.; } \\
\text { SOUZA, F. L. }\end{array}$ & $\begin{array}{l}\text { S A N A R E, Sobral, v.12, n.1, } \\
\text { p.46-53, } 2013\end{array}$ & $\begin{array}{l}\text { Investigar a utilização e } \\
\text { o conhecimento sobre } \\
\text { plantas medicinais } \\
\text { pelos participantes } \\
\text { dos grupos de } \\
\text { convivência dos } \\
\text { Centros de Saúde da } \\
\text { Família (CSF) do Alto da } \\
\text { Brasília, Expectativa e } \\
\text { Estação. }\end{array}$ \\
\hline LILACS & $\begin{array}{l}\text { Potencial terapêutico e } \\
\text { uso de plantas } \\
\text { medicinais em uma área } \\
\text { de Caatinga no estado do } \\
\text { Ceará, nordeste do Brasil }\end{array}$ & Português & $\begin{array}{l}\text { RIBEIRO, D. A.; } \\
\text { MACÊDO, D. G.; } \\
\text { OLIVEIRA, L. G. S.; } \\
\text { SARAIVA, M. E.; } \\
\text { OLIVEIRA, S. F.; } \\
\text { SOUZA, M. M. A.; } \\
\text { MENEZES, I.R.A. }\end{array}$ & $\begin{array}{l}\text { Rev. Bras. Pl. Med., } \\
\text { Campinas, v.16, n.4, p.912- } \\
930,2014\end{array}$ & $\begin{array}{l}\text { Promover um } \\
\text { levantamento das } \\
\text { etnobotânico das } \\
\text { plantas medicinais, } \\
\text { verificando do } \\
\text { versatilidade das } \\
\text { espécies utilizadas e o } \\
\text { consenso de uso e/ou } \\
\text { conhecimento entre os } \\
\text { informantes, do } \\
\text { Distrito de Aratama, no } \\
\text { Município de Assaré, } \\
\text { Ceará }\end{array}$ \\
\hline LILACS & $\begin{array}{l}\text { Estudo } \\
\text { etnofarmacológico e } \\
\text { etnobotânico de } \\
\text { Himatanthus drasticus } \\
\text { (Mart.) Plumel } \\
\text { (janaguba) }\end{array}$ & Português & $\begin{array}{lr}\text { SOARES, } & \text { F.P.; } \\
\text { FRAGA, } & \text { A.F.; } \\
\text { NEVES, } & \text { J.P.O.; } \\
\text { ROMERO, } & \text { N.R.; } \\
\text { BANDEIRA, } & \\
\text { M.A.M. } & \end{array}$ & $\begin{array}{l}\text { Rev. Bras. Pl. Med., } \\
\text { Campinas, v.17, n.4, p.900- } \\
908,2015\end{array}$ & $\begin{array}{l}\text { Realizar levantamentos } \\
\text { etnobotânico e } \\
\text { etnofarmacológico } \\
\text { sobre a espécie H. } \\
\text { drasticus como } \\
\text { contribuição ao } \\
\text { conhecimento } \\
\text { científico da referida } \\
\text { espécie. }\end{array}$ \\
\hline LILACS & $\begin{array}{l}\text { Levantamento } \\
\text { etnobotânico de plantas } \\
\text { medicinais em área de } \\
\text { Caatinga na comunidade } \\
\text { do Sítio Nazaré, } \\
\text { município de Milagres, } \\
\text { Ceará, Brasil }\end{array}$ & Português & $\begin{array}{l}\text { SILVA, C. G.; } \\
\text { MARINHO, M. G. } \\
\text { V.; LUCENA, M. F. } \\
\text { A.; COSTA, J. G. } \\
\text { M. }\end{array}$ & $\begin{array}{l}\text { Rev. Bras. PI. Med., } \\
\text { Campinas, v.17, n.1, p.133- } \\
\text { 142, } 2015\end{array}$ & $\begin{array}{lr}\text { Realizar } & \text { um } \\
\text { levantamento das } \\
\text { plantas medicinais } \\
\text { nativas no bioma } \\
\text { Caatinga na } \\
\text { comunidade do Sítio } \\
\text { Nazaré, no município } \\
\text { de Milagres, Ceará. }\end{array}$ \\
\hline LILACS & 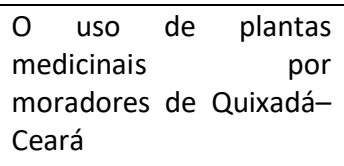 & Português & $\begin{array}{l}\text { OLIVEIRA, D. M. S; } \\
\text { LUCENA, E. M. P. }\end{array}$ & $\begin{array}{l}\text { Rev. Bras. Pl. Med., } \\
\text { Campinas, v.17, n.3, p.407- } \\
412,2015\end{array}$ & $\begin{array}{l}\text { Observar o uso de } \\
\text { plantas medicinais por } \\
\text { moradores de Quixadá- } \\
\text { Ceará. }\end{array}$ \\
\hline LILACS & $\begin{array}{lr}\text { Conhecimento } & \text { de } \\
\text { plantas medicinais e } \\
\text { relação com o ambiente } \\
\text { por alunos de duas } \\
\text { escolas de ensino } \\
\text { fundamental rol do } \\
\text { município de Viçosa do } \\
\text { Ceará, Ceará }\end{array}$ & Português & $\begin{array}{l}\text { OLIVEIRA, I. P. } \\
\text { ARAÚJO, M. P.; } \\
\text { MEIRELES, V. J. S.; } \\
\text { LEMOS, J. R. }\end{array}$ & $\begin{array}{l}\text { Pesquisa em Educação } \\
\text { Ambiental, v.11, n.1, p.81- } \\
93,2016\end{array}$ & $\begin{array}{l}\text { Verificar se há } \\
\text { diferença entre o } \\
\text { conhecimento acerca } \\
\text { do uso medicinal de } \\
\text { plantas apresentado } \\
\text { por alunos de duas } \\
\text { escolas de Ensino } \\
\text { Fundamental da zona } \\
\text { rural e urbana no }\end{array}$ \\
\hline
\end{tabular}




\begin{tabular}{|c|c|c|c|c|c|}
\hline & & & & & $\begin{array}{l}\text { município de Viçosa do } \\
\text { Ceará. }\end{array}$ \\
\hline LILACS & $\begin{array}{l}\text { The conservation of } \\
\text { native priority medicinal } \\
\text { plants in a } \\
\text { Caatinga area in Ceará, } \\
\text { northeastern Brazil }\end{array}$ & Inglês & $\begin{array}{l}\text { SANTOS, M. O.; } \\
\text { ALMEIDA, B. V.; } \\
\text { RIBEIRO, D. A.; } \\
\text { MACÊDO, D. G.; } \\
\text { MACÊDO, M. J. F.; } \\
\text { MACEDO, J. G. F.; } \\
\text { SOUSA, F. F. S.; } \\
\text { OLIVEIRA, L. G. S.; } \\
\text { SARAIVA, M. E.; } \\
\text { ARAÚJO, T. M. S.; } \\
\text { SOUZA, M. M. A. }\end{array}$ & $\begin{array}{l}\text { Academia Brasileira de } \\
\text { Ciências, v.89, n.4, p.2675- } \\
2685,2017\end{array}$ & $\begin{array}{l}\text { Determinar espécies } \\
\text { medicinais que } \\
\text { merecem prioridades } \\
\text { de conservação em } \\
\text { uma área de "Caatinga" } \\
\text { no Nordeste } \\
\text { do território brasileiro. }\end{array}$ \\
\hline LILACS & $\begin{array}{l}0 \quad \text { conhecimento } \\
\text { etnográfico dos } \\
\text { Tremembé da Barra do } \\
\text { Mundaú, Ceará }\end{array}$ & Português & $\begin{array}{l}\text { PINTO, A. L. A.; } \\
\text { MATOS, M. J.; } \\
\text { RUFINO, M. S. M. }\end{array}$ & $\begin{array}{l}\text { INTERAÇÕES, } \\
\text { Grande, v.19, n.1, p.15-28, } \\
2018\end{array}$ & $\begin{array}{l}\text { Compreender } \\
\text { conhecimento } \\
\text { tradicional dos } \\
\text { Tremembé da Barra do } \\
\text { Mundaú acerca das } \\
\text { frutas nativas de seu } \\
\text { território e oferecer } \\
\text { uma contribuição para } \\
\text { a etnobotânica dos } \\
\text { indígenas do Nordeste. }\end{array}$ \\
\hline SciELO & $\begin{array}{l}\text { Ethnopharmacological } \\
\text { use of medicinal plants in } \\
\text { infections by residents of } \\
\text { the Chapada do Araripe, } \\
\text { Crato, } \\
\text { Ceará - Brazil }\end{array}$ & Inglês & $\begin{array}{l}\text { OLIVEIRA, R. D.; } \\
\text { JÚNIOR, F. E. B.; } \\
\text { SAMPAIO, L. A.; } \\
\text { TORRES, J. C.; } \\
\text { RAMOS, A. G. B.; } \\
\text { NUNES, A. A. }\end{array}$ & $\begin{array}{l}\text { Rev. Bras. Promoç. Saúde, } \\
\text { Fortaleza, 25(3): 278-286, } \\
\text { jul./set., } 2012\end{array}$ & $\begin{array}{l}\text { Conhecer o uso } \\
\text { etnofarmacológico de } \\
\text { plantas no tratamento } \\
\text { de infecções do trato } \\
\text { geniturinário (ITU) por } \\
\text { mulheres residentes no } \\
\text { município de Crato, na } \\
\text { Chapada do Araripe, no } \\
\text { interior do Estado do } \\
\text { Ceará, Brasil. }\end{array}$ \\
\hline SCIELO & $\begin{array}{l}\text { Uso de plantas } \\
\text { medicinais cultivadas } \\
\text { em uma área de caatinga } \\
\text { em Assaré - Ceará }\end{array}$ & Português & $\begin{array}{l}\text { MACÊDO, M. S.; } \\
\text { RIBEIRO, D. A.; } \\
\text { SOUZA, M. M. A. }\end{array}$ & $\begin{array}{l}\text { Cad. Cult. Ciênc., v.12, n.1, } \\
2013\end{array}$ & $\begin{array}{lr}\text { Promover } & \text { um } \\
\text { levantamento } & \\
\text { etnobotânico } & \text { de } \\
\text { espécies } & \text { vegetais } \\
\text { pertencentes a região } \\
\text { de Assaré no Estado do } \\
\text { Ceará. }\end{array}$ \\
\hline SciELO & $\begin{array}{lr}\text { Prioridade } & \text { de } \\
\text { conservação } & \text { para } \\
\text { espécies } & \text { medicinais } \\
\text { lenhosas em uma área de } \\
\text { caatinga, Assaré, Ceará, } \\
\text { Brasil }\end{array}$ & Português & $\begin{array}{l}\text { RIBEIRO, D. A.; } \\
\text { MACÊDO, M. S.; } \\
\text { ARAÚJO, T. M. S.; } \\
\text { DA SILVA, M. A. } \\
\text { P.; } \\
\text { LACERDA, S. R.; } \\
\text { SOUZA, M. M. A. }\end{array}$ & $\begin{array}{l}\text { Cad. Cult. Ciênc. Ano VIII, } \\
\text { v.12, n.1, Jul, } 2013\end{array}$ & $\begin{array}{l}\text { Determinar espécies } \\
\text { medicinais lenhosas } \\
\text { prioritárias para } \\
\text { conservação em uma } \\
\text { área de caatinga no } \\
\text { estado do Ceará, } \\
\text { nordeste do Brasil. }\end{array}$ \\
\hline SCIELO & $\begin{array}{l}\text { Uso da Myracroduon } \\
\text { urundeuva Allemão } \\
\text { (aroeira do } \\
\text { sertão) pelos agricultores } \\
\text { no tratamento de } \\
\text { doenças }\end{array}$ & Português & $\begin{array}{l}\text { PEREIRA, P. S.; } \\
\text { BARROS, L. M.; } \\
\text { BRITO, A. M.; } \\
\text { DUARTE, A. E.; } \\
\text { MAIA, A. J. }\end{array}$ & $\begin{array}{l}\text { Revista Cubana de Plantas } \\
\text { Medicinales 2014;19(1):51- } \\
60\end{array}$ & $\begin{array}{l}\text { Levantar os principais } \\
\text { usos fitoterápicos e os } \\
\text { benefícios da planta } \\
\text { Myracroduon } \\
\text { urundeuva Fr. Allemão } \\
\text { entre os agricultores de } \\
\text { uma cidade do interior } \\
\text { do Ceará. }\end{array}$ \\
\hline SCIELO & $\begin{array}{l}\text { O estudo etnobotânico } \\
\text { de Pterodon emarginatus } \\
\text { Vogel na área rural do } \\
\text { município de Jardim - CE }\end{array}$ & Português & $\begin{array}{l}\text { PEREIRA, P. S.; } \\
\text { DRUMOND, M. } \\
\text { A.; BARROS, L. M.; } \\
\text { MAIA, A. J. }\end{array}$ & $\begin{array}{l}\text { VIII Simpósio Brasileiro de } \\
\text { Pós-Graduação em Ciências } \\
\text { Florestais. Recife, } 2014 .\end{array}$ & $\begin{array}{l}\text { Realizar o estudo } \\
\text { etnobotânico da } P \text {. } \\
\text { emarginatus (sucupira- } \\
\text { branca) na comunidade } \\
\text { rural da cidade de } \\
\text { Jardim-CE. }\end{array}$ \\
\hline & Comunidade & & & & $\begin{array}{lr}\begin{array}{l}\text { Promover um } \\
\text { com }\end{array} & \begin{array}{r}\text { estudo } \\
\text { alunos, }\end{array} \\
\text { professores } & \mathrm{e} \\
\text { moradores } & \mathrm{da} \\
\text { comunidade } & \mathrm{de} \\
\end{array}$ \\
\hline
\end{tabular}




\begin{tabular}{|c|c|c|c|c|c|}
\hline SciELO & $\begin{array}{l}\text { escolar na valorização do } \\
\text { conhecimento } \\
\text { sobre plantas medicinais }\end{array}$ & Português & $\begin{array}{l}\text { CARNEIRO, M. S.; } \\
\text { SILVEIRA, A. P.; } \\
\text { GOMES, V. S. }\end{array}$ & $\begin{array}{l}\text { Revista Biotemas, v.29, n.2, } \\
2016\end{array}$ & $\begin{array}{l}\text { Córrego da Ema, } \\
\text { Amontada, Ceará - } \\
\text { Brasil, visando } \\
\text { conhecer os saberes } \\
\text { sobre } \\
\text { plantas medicinais em } \\
\text { uma pequena } \\
\text { comunidade rural do } \\
\text { semiárido brasileiro. }\end{array}$ \\
\hline SCIELO & $\begin{array}{l}\text { Ethnobiological survey of } \\
\text { plants and animals used } \\
\text { for the treatment of } \\
\text { acute respiratory } \\
\text { infections in children of a } \\
\text { traditional community in } \\
\text { the } \\
\text { Municipality of Barbalha, } \\
\text { Ceará, Brazil. }\end{array}$ & Inglês & 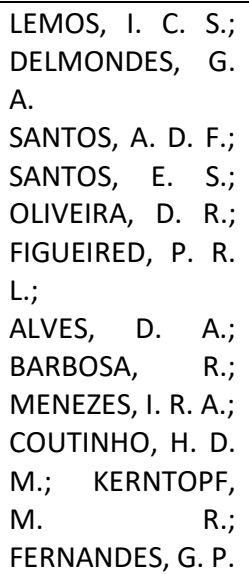 & $\begin{array}{l}\text { Afr. J. Tradit. Complement } \\
\text { AlternMed., v.13, n.4, p.166- } \\
175,2016\end{array}$ & $\begin{array}{lr}\text { Realizar análises } \\
\text { etnobiológicas } \\
\text { levantamento de } \\
\text { plantas e animais } \\
\text { utilizados no } \\
\text { tratamento de } \\
\text { infecções respiratórias } \\
\text { agudas em crianças de } \\
\text { uma comunidade } \\
\text { tradicional da } \\
\text { município de Barbalha, } \\
\text { Ceará, Brasil. }\end{array}$ \\
\hline SciELO & $\begin{array}{l}\text { Uso de fitoterápicos por } \\
\text { mulheres do município } \\
\text { de Tauá, Ceará, Brasil }\end{array}$ & Português & 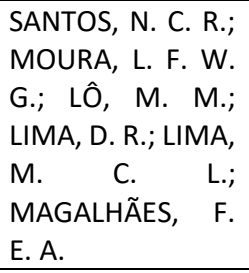 & BioFarm, v.13, n.4, 2017 & $\begin{array}{l}\text { Reporta o uso de } \\
\text { fitoterápicos por } \\
\text { mulheres do Município } \\
\text { de Tauá, Ceará, Brasil. }\end{array}$ \\
\hline SciELO & $\begin{array}{l}\text { O saber etnobotânico } \\
\text { sobre plantas medicinais } \\
\text { na Comunidade da } \\
\text { Brenha, Redenção, CE }\end{array}$ & Português & $\begin{array}{l}\text { SANTOS, L. S. N.; } \\
\text { SALLES, M. G. F.; } \\
\text { PINTO, C. M.; } \\
\text { PINTO, O. R. O.; } \\
\text { RODRIGUES, I. C. } \\
\text { S. }\end{array}$ & $\begin{array}{l}\text { AGRARIAN ACADEMY, } \\
\text { Centro Científico Conhecer - } \\
\text { Goiânia, v.5, n.9, p.4 } 09 \text {, } \\
2018\end{array}$ & $\begin{array}{l}\text { Realizar um } \\
\text { levantamento } \\
\text { etnobotânico sobre o } \\
\text { conhecimento e uso } \\
\text { das plantas medicinais } \\
\text { e suas aplicações pelos } \\
\text { comunitários da } \\
\text { Brenha, que foi } \\
\text { realizado por } \\
\text { entrevistas duas vezes } \\
\text { por semana utilizando } \\
\text { um } \\
\text { questionário } \\
\text { estruturado. }\end{array}$ \\
\hline Mediline & $\begin{array}{l}\text { The coexistence of } \\
\text { traditional medicine and } \\
\text { biomedicine: a study } \\
\text { with local health experts } \\
\text { in two Brazilian regions }\end{array}$ & Inglês & $\begin{array}{l}\text { ZANK, } \\
\text { HANAZAKI, N. }\end{array}$ & $\begin{array}{l}\text { PLoS One, v.12, n.4, p. } \\
\text { e0174731, } 2017\end{array}$ & $\begin{array}{l}\text { Investigar o uso da } \\
\text { medicina tradicional e } \\
\text { da biomedicina em } \\
\text { comunidades de duas } \\
\text { regiões distintas, a } \\
\text { região semiárida do } \\
\text { nordeste do Brasil e a } \\
\text { região costeira do sul } \\
\text { do Brasil }\end{array}$ \\
\hline
\end{tabular}

Diante dos dados apresentados, ficou constatado que dos materiais encontrados há um binômio quanto a linguagem, sendo definidos como 4 artigos em inglês e o restante na língua portuguesa. Para tanto, todos estavam dentro da temática da produção científica em plantas medicinais no Ceará, abordando ou não o conceito original da etnobotânica em si.

Nota-se que diante dos achados, os estudos ainda são bastante escassos diante do período estabelecido no momento de busca, já que de uma certa forma, a área de pesquisas em produtos naturais encontra-se bem firmada como ciência no decorrer das últimas décadas, principalmente no cenário de saúde. 
Rocha et al. (2017) chama bastante atenção para o aspecto do cultivo dinâmico das plantas medicinais pelas populações, de modo que tal prática tem se tornado uma alternativa terapêutica dentro de hábitos brasileiros.

Estudos recentes comprovam que $80 \%$ da população mundial possuem confiança quanto ao uso de ervas medicinais, principalmente por aderirem ao método relativo de cultivo e o uso de consumo diário (FIRMO et al., 2011). Com base nos referentes dados, é notório perceber que as investigações no campo em questão já perpetuam por um bom tempo, o que poderia resultar teoricamente no grande número de periódicos produzidos.

O Ceará possui laços fortes na cultura de seu povo, principalmente aqueles pertencentes a etnia indígena, de maneira a tornar os medicamentos naturais como elemento primordial de suas tradições. Souza et al. (2019) conseguiram trazer por meio de investigação histórica minuciosa a identidade de uma saúde alternativa dentro da comunidade Potyguara, elencando a importância social com base nos efeitos curativos produzidos a partir de seus manejos.

Outro fator que merece atenção como ponto de partida de nosso estudo, seria a utilização do termo "Etnobotânica" no seu real sentido, de modo que seu conceito, por mais que recente no significado original e amplo se remetesse a relação direta do homem e planta no sentido medicinal. Nas publicações encontradas nesta pesquisa, apenas Rosa et al. (2009), Pereira et al. (2014), Soares et al. (2015), Silva et al. (2015) e Santos et al. (2018) utilizaram em seu título o referente termo, condizendo especificamente com o objetivo do trabalho realizado.

Em contrapartida, podemos perceber também conforme tabela 2 que alguns sinônimos ou subárea da etnobotânica também foram colocados, cita-se, a "Etnobiologia" por Leno et al. (2016); "Etnografia" por Pinto et al. (2018) e "Etnofarmacologia" por Oliveira et al. (2012), todos realizados dentro da perspectiva cearense. Para Franco et al. (2011) a etnobotânica funciona como uma ferramenta eficaz do homem e a vasta riqueza vegetal presente ao seu redor empregando utilização em enfermidades, rituais religiosos ou até mesmo em padrões de alimentação, evidenciando as características peculiares de um determinado grupo.

Já com relação as regiões estudadas, Junior et al. (2012) abordou Chapada do Araripe, especificamente na cidade de Crato, já Macêdo et al. (2013) e Ribeiro et al. (2013) focaram no Município de Assaré. A cidade de Sobral foi o local pesquisado por Nascimento et al. (2013), enquanto que, Pereira et al. (2014) referenciou Jardim. Outros municípios pesquisados foram Milagres (silva et al., 2015), Quixadá (OLIVEIRA et al., 2015), Viçosa do Ceará (OLIVEIRA et al., 2016), Tauá (SANTOS et al., 2017), Redenção (SANTOS et al., 2018), Amontada (CARNEIRO et al., 2016) e Itapipoca (PINTO et al., 2018). Esses dados podem ser verificados no quadro 3, que especifica a distribuição de produções por regiões e cidades cearenses.

Quadro 3: Distribuição das produções de acordo com as regiões e ano de publicação.

\begin{tabular}{|l|l|l|}
\hline Produções & Ano & Região \\
\hline Os aspectos etnobotânicos da copaíba & 2009 & Não especifica \\
\hline $\begin{array}{l}\text { Ethnopharmacological use of medicinal plants in infections } \\
\text { By residents of the Chapada do Araripe, Crato, } \\
\text { Ceará - Brazil }\end{array}$ & 2012 & Crato - CE \\
\hline Plantas medicinais e sua utilização pelas & 2013 & Sobral - CE \\
\hline
\end{tabular}




\begin{tabular}{|c|c|c|}
\hline comunidades do Município de Sobral, Ceará & & \\
\hline $\begin{array}{l}\text { Uso de plantas medicinais cultivadas } \\
\text { em uma área de caatinga em Assaré - Ceará }\end{array}$ & 2013 & Assaré - CE \\
\hline $\begin{array}{l}\text { Prioridade de conservação para espécies medicinais lenhosas em uma área de caatinga, Assaré, } \\
\text { Ceará, Brasil }\end{array}$ & 2013 & Assaré - CE \\
\hline $\begin{array}{l}\text { Potencial terapêutico e uso de plantas medicinais em uma área de Caatinga no estado do Ceará, } \\
\text { nordeste do Brasil }\end{array}$ & 2014 & $\begin{array}{l}\text { Distrito } \\
\text { Aratama } \\
\text { Assaré - CE }\end{array}$ \\
\hline $\begin{array}{l}\text { Uso da Myracroduon urundeuva Allemão (aroeira do } \\
\text { sertão) pelos agricultores no tratamento de doenças }\end{array}$ & 2014 & Jardim - CE \\
\hline O estudo etnobotânico de Pterodon emarginatus Vogel na área rural do município de Jardim - CE & 2014 & Jardim-CE \\
\hline $\begin{array}{l}\text { Estudo etnofarmacológico e etnobotânico de Himatanthus drasticus (Mart.) Plumel } \\
\text { (janaguba) }\end{array}$ & 2015 & $\begin{array}{l}\text { Crato - CE } \\
\text { Fortaleza - CE } \\
\text { Pacajus - CE }\end{array}$ \\
\hline $\begin{array}{l}\text { Levantamento etnobotânico de plantas medicinais em área de Caatinga na comunidade do Sítio } \\
\text { Nazaré, município de Milagres, Ceará, Brasil }\end{array}$ & 2015 & Milagres - CE \\
\hline O uso de plantas medicinais por moradores de Quixadá-Ceará & 2015 & Quixadá - CE \\
\hline $\begin{array}{l}\text { Conhecimento de plantas medicinais e relação com o ambiente por alunos de duas escolas de ensino } \\
\text { fundamental do município de Viçosa do Ceará, Ceará }\end{array}$ & 2016 & $\begin{array}{l}\text { Viçosa do Ceará- } \\
\text { CE }\end{array}$ \\
\hline $\begin{array}{l}\text { Ethnobiological survey of plants and animals used for the treatment of } \\
\text { acute respiratory infections in children of a traditional community in the } \\
\text { Municipality of Barbalha, Ceará, Brazil. }\end{array}$ & 2016 & Barbalha - CE \\
\hline $\begin{array}{l}\text { Comunidade rural e escolar na valorização do conhecimento } \\
\text { sobre plantas medicinais }\end{array}$ & 2016 & Amontada-CE \\
\hline Uso de fitoterápicos por mulheres do município de Tauá, Ceará, Brasil & 2017 & Tauá - CE \\
\hline $\begin{array}{l}\text { The conservation of native priority medicinal plants in a } \\
\text { Caatinga area in Ceará, northeastern Brazil }\end{array}$ & 2017 & Milagres - CE \\
\hline $\begin{array}{l}\text { The coexistence of traditional medicine and biomedicine: a study with local health experts in two } \\
\text { Brazilian regions }\end{array}$ & 2017 & Milagres - CE \\
\hline O conhecimento etnográfico dos Tremembé da Barra do Mundaú, Ceará & 2018 & $\begin{array}{l}\text { Barra do Mundaú } \\
- \text { CE }\end{array}$ \\
\hline O saber etnobotânico sobre plantas medicinais na Comunidade da $\mathrm{Br}$ & 2018 & Redenção - CE \\
\hline
\end{tabular}

É notório que a maior parte das produções apresentados deriva de regiões semiárido cearense, com a maioria deles concentrados na cidade de Assaré e Milagres. Tais achados podem ter relação com a forte base religiosa presente nesses locais, de maneira que as plantas medicinais integram a cultura local ou até mesmo o turismo religioso, que na prática funciona como uma fonte de renda alternativa para esses moradores (DUARTE et al., 2016).

O estado do Ceará foi contemplado por meio do Decreto n. 30.016, de 30 de dezembro de 2009, sob a Lei Estadual n. 12.951, de 7 de outubro de 1999 que regulariza o uso de fitoterápicos dentro do sistema de saúde pública (RODRIGUES et al., 2011). Nessa abordagem percebe-se o quanto é forte a prática da medicina alternativa nesse panorama, contudo, a formalidade e a ciência corroboram de maneira conjunta para estabelecer o uso seguro de preparos e extratos naturais. Com isso, esse declínio produtivo do arsenal científico implica em um desequilíbrio do ponto de vista dinâmico, já que de certa forma, a região possui matéria prima e sujeito propicia ao levantamento etnobotânico.

O aumento do uso das plantas medicinais ultrapassou barreiras de modo promissor a nível superior, cabe ressaltar que diante da informação, o engajamento da inter-relação universidade-comunidade é essencial para a concretização do meio cultural dentro do universitário (VIRGínIO et al., 2018). Diante do exposto, é imprescindível insistir no fato de que o índice de publicação funciona como um sinal notificador/embasador em etnobotânica no Nordeste Cearense.

Em suma, o estudo pode mostrar o quão pouco as pesquisas em etnobotânica é evidente no Ceará, 
que por sua vez, o uso de sinônimos ou subáreas não influenciou no quantitativo final do apurado. Cabe salientar que diante de um diagnóstico informal, ainda há um déficit na produção e pouco interesse pelo amplo campo medicinal presente nesse polo. Os trabalhos de levantamento ainda tendem a ser maioria no decorrer desses dez anos, pois ainda há uma resistência quanto aos ensaios experimentais, até mesmo pela grande diversidade de espécies e pouco recurso para a realização de tal modalidade, como é exemplo de estudos taxonômicos.

\section{CONCLUSÕES}

Conforme a presente revisão integrativa, a prevalência de trabalho em etnobotânica na visão de plantas medicinais no período estabelecido no Ceará ainda é bastante baixa, evidenciando de um modo geral um campo que proporciona possibilidade a inserção dessa ciência, no entanto, com baixo índice de publicação em comparação com a grande quantidade de espécie pertencente a Caatinga.

Do mesmo modo, recomenda-se o incentivo a realização de uma maior intensificação acadêmica dentro desse aspecto, o que poderia resultar em novas descobertas e comprovações terapêuticas, além do sentido cultural dos grupos que ali residem. Afinal, a pesquisa etnobotânica tente a proporcionar uma série de benefícios, sendo estes de caráter histórico, cultural e social.

\section{REFERÊNCIAS}

ALCORN, J. B.. The scope and aims of ethnobotany in a developing world. In: SCHULTES, R. E.; REIS, S. V.. Ethnobotany: evolution of a discipline. Cambridge, Timber Press, 1995. p.23-39.

AMOROZO, M. C. M.. A abordagem Etnobotânica na Pesquisa de Plantas Medicinais. In: DI-STASI, L. C.. Plantas medicinais: arte e ciência: um guia de estudo interdisciplinar. São Paulo: Universidade Estadual Paulista, 1996. p.47-67.

APOLINARIO, J. R.. Plantas Nativas, indígenas coloniais: usos e apropriações da flora da América Portuguesa. In: LOREAI K.. Usos e circulação de plantas no Brasil. 3 ed. Rio de Janeiro: Kakobsson, 2013. p.323.

BISPO, G. L.; MARCO, C. A.; FERREIRA, F. S.; CHAVES, J. T. L.; FARIAS, R. B.. Estudo etnobotânico de plantas medicinais no comércio da cidade de Juazeiro do Norte, CE. Journal of Biology \& Pharmacy and Agricultural Management, v.15, n.4, 2019.

BRASIL. Conheça os biomas brasileiros: Diversidade biológica. 2009.

BROOME, M. E.. Integrative literature reviews for the development of concepts. In: RODGERS, B. L.; CASTRO, A. A. Revisão sistemática e meta-análise. 2006.

CARVALHO, J. S. B.; MARTINS, J. D. L.; MENDONÇA, M. C. S.; LIMA, L. D.. Uso popular das plantas medicinais na comunidade da Várzea. Revista de Biologia e Ciências da Terra, Garanhuns, v.13, n.12, p.58-65, 2013.

CUNHA, S. A.; BORTOLOTTO, I. M.. Etnobotânica de Plantas
Medicinais no Assentamento Monjolinho, município de Anastácio. Acta Botânica Brasílica, Campo Grande, v.25, n.3, p.685-698, 2011.

DUARTE, C. M.; PEREIRA, A. M. B.; PEREIRA, P. S.; BARROS, L. M.; DUARTE, A. E.. A religiosidade e o turismo em uma cidade do interior do Ceará. Inter Science Place: Revista Científica Internacional, v.11, n.2, 2016.

FIRMO, E. C. A.; MENEZES, V. J. M.; PASSOS, C. E. C.; DIAS, C. N.; ALVES, L. P. L.; DIAS, I. C. L.; NETO, M. S.; OLEA, R. S. G. Contexto histórico, uso popular e concepção científica sobre plantas medicinais. Cad. Pesq., São Luís, v.18, 2011.

FRANCO, F.; FERREIRA, A. P. N. L.; FERREIRA, M. L.. Etnobotânica: aspectos históricos e aplicativos desta ciência. Caderno de Cultura e Ciência, v.10, n.2, 2011.

HAMILTON, A. C.; SHENGJI, P.; KESSY, J.; KHAN, A. A.; LAGOSWITTE, S.; SHINWARI, Z. K.. The purposes and teaching of Applied Ethnobotany. Godalming, People and Plants Working Paper, v.11, 2003.

LINHARES, J. F. P.; RODRIGUES, M. I. A.; FREITAS, P. F.; PINHEIRO, G. U. B.. Etnobotânica histórica das plantas do Maranhão no século XVII baseada na obra de Cristóvão de Lisboa. Biota Amazônia, Macapá, v.8, n.3, p.15-18, 2018.

MACIEL, M. A. M.; PINTO, A. C.; VEIGA JUNIOR, V. F.. Plantas medicinais: a necessidade de estudos multidisciplinares. Revista Química Nova, v.23, n.3, p.429-438, 2002.

MIRANDA, T. M.; HANAZAKI, N.. Conhecimento e uso de recursos vegetais de restinga por comunidades das ilhas do Cardoso (SP) e de Santa Catarina (SC), Brasil. Acta Botânica 
Brasílica, v.22, p.203-215, 2008.

OLIVEIRA, F. C. S.; BARROS, R. F. M.; MOITA NETO, J. M.. Plantas medicinais utilizadas em comunidades rurais de Oeiras, semiárido piauiense. Rev. Bras. PI. Med., Botucatu, v.12, n.3, p.282-301, 2010.

OLIVEIRA, F. C.; ALBUQUERQUE, U. P.; FONSECA-KRUEL, V. S.; HANAZAKI, N.. Avanços nas pesquisas etnobotânicas no Brasil. Acta Botânica Brasílica, v.23, n.2, p.590-605, 2009.

OLIVEIRA, I. G.; CARTAXO, S. L.; SILVA, M. A. P.. Plantas Medicinais Utilizadas na Farmacopeia Popular em Crato, Juazeiro e Barbalha (Ceará, Brasil). Revista Brasileira de Biociências, Porto Alegre, v.5, n.1, p.189-191, 2007.

RIBEIRO, D. A.; MACÊDO, D. G.; OLIVEIRA, L. G. S.; SARAIVA, M. E.; OLIVEIRA, S. F.; SOUZA, M. M. A.; MENEZES, I. R. A.. Potencial terapêutico e uso de plantas medicinais em uma área de Caatinga no estado do Ceará, nordeste do Brasil. Rev. Bras. PI. Med., Campinas, v.16, n.4, p.912-930, 2014.

ROCHA, M. S.; WEISS P. F.; FERREIRA, A. D.; BETTANZOS, A. C.. Representações sociais de profissionais da saúde acerca das plantas medicinais. Rev. Cubana Enfermagem, v.33, n.2, 2017.

RODRIGUES, A. G.; SANTOS, M. G.; SIMONI, C.. Fitoterapia na saúde da família. In: Sociedade Brasileira de Medicina de Família e Comunidade. Programa de Atualização em Medicina de Família e Comunidade (PROMEF). Artmed, Porto Alegre, p.131-65, 2011.

SANTOS, D. R. V.; SANTOS, J. V.; ANDRADE, W. M.; LIMA, T. M. S.; LIMA, L. N.; LIMA, A. G. D.; ANDRADE, M. J. G.; SANTOS, M. A. V.; MOURA, G. J. B.; NUNES, E. S.. Plantas antiparasitárias utilizadas pelos indígenas Kantaruré-Batida (NE-Brasil): Etnobotânica e riscos de erosão dos saberes locais1. Ambiente \& Sociedade, São Paulo, v.21, 2018.

SILVA, C. G.; MARINHO, M. G. V.; LUCENA, M. F. A.; COSTA, J. G. M.. Levantamento etnobotânico de plantas medicinais em área de Caatinga na comunidade do Sítio Nazaré, município de Milagres, Ceará, Brasil. Rev. Bras. PI. Med. Campinas, v.17, n.1, p.133-142, 2015.

SOUSA, M. L. T.; CAPRARA, A.. Saúde indígena potyguara: por outras configurações políticas e estéticas na Saúde Coletiva. Physis: Revista de Saúde Coletiva, Rio de Janeiro, v.29, n.2, 2019

SOUSA, R. F.; SILVA, R. S. R. A.; ROCHA, T. G. F.; SANTANA, J. A. S.; VIEIRA, F. A.. Etnoecologia e Etnobotânica da Palmeira carnaúba no semiárido brasileiro. Cerne, v.21, n.4, p.587594, 2015.

SOUZA, C. M. P.; BRANDÃO, D. O.; SILVA, M. S. P.; PALMEIRA, A. C.; SIMÕES, M. O. S.; MEDEIROS, A. C. D.. Utilização de Plantas Medicinais com Atividade Antimicrobiana por Usuários do Serviço Público de Saúde em Campina Grande - Paraíba. Rev. Bras. PI. Med., Campinas, v.15, n.2, p.188-193, 2013.

SOUZA, M. T.; SILVA, M. D.; CARVALHO, R.. Revisão integrativa: o que é e como fazer? Einstein, v.8, n.1, p.102106, 2010.

TEIXEIRA, A. H.; BEZERRA, M. M.; CHAVES, H. V.; VAL, D. R.; FILHO, S. M. P.; SILVA, A. F. R.. Conhecimento popular sobre o uso de plantas medicinais no Município de Sobral-Ceará, Brasil. S A N A R E, Sobral, v.13, n.1, p. 23-28, 2014.

TOLEDO, M. M.. A vulnerabilidade do adolescente ao HIV/AIDS. Dissertação (Mestrado em Enfermagem) Universidade de São Paulo, São Paulo, 2008.

VIRGÍNIO, T. B.; CASTRO, K. S.; LIMA, A. L. A.; ROCHA, J. V.; BONFIM, I. M.. A utilização de plantas medicinais por pacientes hipertensos e diabéticos: estudo transversal no nordeste brasileiro. Rev. Bras. Promoç. Saúde, v.31, n.4, p.110, 2018.

ZURLO, C.; BRANDÃO, M.. As Ervas comestíveis: descrição, ilustração e receitas. Coleção do agricultor: Globo. Rio de Janeiro, p.19-55, 1989.

A CBPC - Companhia Brasileira de Produção Científica (CNPJ: 11.221.422/0001-03) detém os direitos materiais desta publicação. Os direitos referem-se à publicação do trabalho em qualquer parte do mundo, incluindo os direitos às renovaç̃ões, expansões e disseminações da contribuiç̃o, bem como outros direitos subsidiários. Todos os trabalhos publicados eletronicamente poderão posteriormente ser publicados em coletâneas impressas sob coordenação da Sustenere Publishing, da Companhia Brasileira de Produção Científica e seus parceiros autorizados. Os (as) autores (as) preservam os direitos autorais, mas não têm permissão para a publicação da contribuição em outro meio, impresso ou digital, em português ou em tradução. 